DOI 10.37882/2223-2982.2021.04-2.29

\title{
СОПОСТАВИТЕЛЬНЫЙ АНАЛИЗ ЛИНГВОСТИЛИСТИЧЕСКИХ ОСОБЕННОСТЕЙ НОМИНАЦИЙ ДОКУМЕНТОВ О ШКОЛЬНОМ, ПРОФЕССИОНАЛЬНОМ И ВЫСШЕМ ОБРАЗОВАНИИ В ОБРАЗОВАТЕЛЬНОМ ДИСКУРСЕ НЕМЕЦКОГО И РУССКОГО ЯЗЫКОВ
}

\begin{abstract}
COMPARATIVE ANALYSIS OF
LINGUISTIC AND STYLISTIC FEATURES

OF EDUCATIONAL DOCUMENTS OF

SECONDARY, UPPER SECONDARY

AND HIGHER EDUCATION IN THE

EDUCATIONAL DISCOURSE OF GERMAN

AND RUSSIAN LANGUAGES
\end{abstract}

T. Rudenko

Summary: The aim of the study is to identify the linguistic and stylistic features of the German and Russian educational discourses based on the names of educational documents. The scientific novelty lies in the fact that the linguistic and stylistic features of the educational discourse are first time investigated by a comparative analysis of the nominations of various types of documents issued after graduation from educational organizations in Germany and Russia. The results showed that the linguistic and stylistic features of the mentioned units are manifested in the phenomena of synonymy, the presence of territorial duplets, and non-equivalent vocabulary.

Keywords: educational discourse, document on education, synonym, territorial doublet, non-equivalent vocabulary.

\section{Ввехение}

$\mathrm{O}$ бразовательный дискурс неоднократно становился объектом специального исследования, в том числе в работах И.Н. Богуцкой [3], Е.В. Добреньковой [4], Б.В. Пенькова [8], П.Р. Юзманова [14] и др., которые послужили теоретической базой данного исследования.

Под образовательным дискурсом мы понимаем систему ценностно-смысловой коммуникации субъектов образовательного процесса, концептуальную сферу которой составляет образование как исторически сложившаяся общенациональная система образовательных учреждений и органов управления ими [2, с. 7].

Формой репрезентации образовательного дис-
Руденко Татьяна Ивановна

старший преподаватель, Московский педагогический государственный университет ti.rudenko@mpgu.edu

Аннотация: Цель исследования - выявить лингвостилистические особенности немецкоязычного и русскоязычного образовательных дискурсов на материале наименований документов об образовании. Научная новизна заключается в том, что лингвостилистические особенности образовательного дискурса впервые исследуются путем сопоставительного анализа номинаций различных видов документов, выдаваемых по окончании образовательных организаций в Германии и России. Полученные результаты показали, что лингвостилистические особенности вышеуказанных единиц проявляются в явлениях синонимии, наличии территориальных дуплетов, безэквивалентной лексике.

Ключевые слова: образовательный дискурс, документ об образовании, синоним, территориальный дублет, безэквивалентная лексика. курса могут являться нормативно-правовые акты, а также другие виды документации, обеспечивающие функционирование системы образования и отдельных учреждений этой системы, в том числе текстовые материалы, опубликованные на официальных сайтах органов управления образованием и учреждений образования.

Мы опираемся на понятие системы образования как исторически сложившейся общенациональной системы образовательных учреждений и органов управления ими [12, с. 161-163]. Специфику образовательного дискурса определяют ее конституциональные черты (в рамках отдельных государственных, территориальных или иных образований), а также вся совокупность общественных отношений: идеологических, правовых, социальных, экономических, этических и др. 
Объектом данного исследования являются номинации официальных документов об окончании учебного заведения, подтверждающие получение определенного уровня образования либо присвоение соответствующей квалификации, выдаваемые учебными заведениями ФРГ и России.

Предметом изучения выступают лингвостилистические особенности указанных лексических единиц.

Актуальность нашего исследования обусловлена:

1. недостаточным уровнем разработки в современной лингвистической науке вопросов образовательного дискурса, его специфики, в том числе на материале нормативно-правовых актов и официальных документов;

2. потребностью более пристального изучения лингвостилистических особенностей единиц, составляющих дискурсивную область документы об образовании, для определения основных характеристик образовательного дискурса немецкого и русского языков;

3. необходимостью проведения сопоставительного анализа единиц исследуемых языков для выявления специфики образовательного дискурса на данном этапе исследования.

Практическая значимость работы связана с возможностью использования ее результатов при переводе специальных текстов, в теоретических разработках и лекционных курсах по теории и практике перевода, межкультурной коммуникации, лингвокультурологии и лингвострановедению.

В качестве методов исследования использовались следующие:

1. сопоставительный метод;

2. описательный метод;

3. метод сплошной выборки;

4. количественный метод.

Для достижения цели исследования необходимо решение ряда задач:

1. выявить лексические единицы, входящие в образовательный дискурс немецкого языка, используемые для номинации различных видов документов об образовании, используемые в текстах нормативно-правовых актов и других текстовых источников;

2. выявить лексические единицы, входящие в образовательный дискурс русского языка, используемые для номинации различных видов документов об образовании, используемые в текстах нормативно-правовых актов и других текстовых источников;

3. провести сопоставительный анализ указанных единиц и определить их лингвостилистические особенности.

Материалом исследования послужили: лексикографические источники, представленные общенемецкими словарями и словарями современного русского языка, а также специальными словарями, глоссариями Болонского процесса; текстовые источники, представленные нормативно-правовыми актами, текстовыми материалами, опубликованными на официальных сайтах Министерств и образовательных порталах Германии и России [5-7; 10; 15-36].

\section{1. Лексические единишы, используемые мия номинации Аокументов об образовании в ФРГ}

Особенности образовательного дискурса в немецком языке определены спецификой государственного устройства ФРГ как федеративного государства, имеющего в своем составе 16 равноправных субъектов - федеральных земель.

На всей территории Германии школьное образование разделено на три ступени: начальная ступень (Primarstufe), к которой относится обучение в начальной школе с 1 - 4 классы; первая ступень среднего образования (Sekundarstufe I), охватывающая обучение с 5 по 10 классы в разных типах школ; вторая ступень среднего образования (Sekundarstufe II), обучение по которой проходит в школах, имеющих старшие классы, в учреждениях профессионального образования, школах повышения квалификации для взрослых. На федеральном уровне система школьного образования регулируется Основном законом Федеративной Республики Германии (статья 7) [18]. Однако каждая федеральная земля имеет свой собственный закон, определяющий работу образовательных организаций данного уровня, поэтому наименования учреждений и документов, свидетельствующих об их окончании, могут существенно отличаться.

Обращаясь к системе высшего образования Германии, стоит отметить, что с 1999 года ФРГ является одной из стран-участник Болонского процесса [17], главная цель которого - создание единого Европейского пространства высшего образования с единой квалификационной базой и взаимным признанием степеней для всех высших учебных заведений. Работа высших учебных заведений Германии регулируется федеральным законом Об университетской структуре [24] и локальными нормативными актами регионов.

В нормативно-правовых актах ФРГ виды документов, выдаваемых по окончании обучения, обозначены следующими терминами:

1. Abgangszeugnis - свидетельство об окончании учебного заведения [1], выдаваемое учащимся, не 
достигшем образовательных целей [22, р. 17];

2. Abschlusszeugnis - свидетельство об окончании. Данная лексическая единица имеет несколько вариантов перевода на русский язык, так как объединяет все типы документов об образовании, выдаваемых в системе школьного, профессионального и высшего образования: свидетельство об окончании (вуза, курсом), переводное свидетельство, аттестат об окончании среднего учебного заведения, выпускное свидетельство, выпускной ammecmam [1]. В русскоязычных текстовых материалах, размещенных на официальных сайтах Министерств образования и культуры Германии, тип документы, выдаваемых по окончании школьных учебных заведений, обозначен термином ammecmam [15; 19]. В этой связи для передачи на русский язык наименований документов школьного образования, содержащих в своем названии $\boldsymbol{A} \boldsymbol{b}$ schlusszeugnis или короткую форму данного существительного Abschluss [21], в нашем исследовании мы также используем лексему ammecmam.

Ниже рассматриваются лексические единицы, обозначающие виды документов школьной системы образования. В зависимости от учебного заведения, его направленности и сроков обучения, документы об образовании можно объединить в синонимические ряды:

\section{1) «Aтmестат о неполном среднем образовании».}

Erster allgemeinbildender Schulabschluss - general education school leaving certificate that may be obtained in all Länder at the end of the ninth school year [22, p. 95] / Amтестат об окончании средней школы, который можно получить во всех землях по окончании девятого класса. Лексема функционирует на территории двух регионов (Гамбург [35] и Шлезвиг-Гольштейн [28]).

Согласно описанию, указанному в «Европейском глоссарии по образованию» [22], синонимами номинации выступают следующие лексемы: Hauptschulabschluss, функционирующая в пяти землях [26; 29; 31-33], Вerufsreife, использующаяся в трех регионах [16; 30; 35], Berufsbildungsreife, функционирующая в трех землях[19-20; 29].

В Бранденбурге и Гамбурге допустимо использование двух лексических единиц, различия заключаются в типе учебного заведения, по окончании которого выдается документ.

Синонимия всех вышеперечисленных номинаций обусловлена их территориальной маркированностью, вышеперечисленные лексемы можно считать территориальными дублетами.

2) «Квалификационный атmестат об окончании де- вятого класса основной школы».

В силу различного орфографического оформления, принятого в разных регионах, номинация представлена синонимами Qualifizierender Hauptschulabschluss [23; 36] и Qualifizierter Hauptschulabschluss [27]. Tepриториальным дублетом лексем выступает Qualifizierender Abschluss der Mittelschule (квалифицирующий ammecmam средней школы), который выдается после окончания девятого класса средней школы (Mittelschule) и успешной сдачи экзаменов в свободном государстве Бавария [15].

\section{3) «Aттестат о среднем образовании».}

Mittlere Schulabschluss - general education school leaving certificate awarded by a Realschule or, under certain circumstances, by other types of lower secondary school on completion of the tenth school year [22, p.151] / Ammecmam of окончании средней школы, выдаваемый в Realschule или, при определенных обстоятельствах, другими типами учреждений первой ступени средней школы по окончании десятого года обучения. Номинация используется на территории четырех земель [19-20; 28; 32].

В ряде регионов функционируют следующие синонимы: Realschulabschluss [15; 29; 33], Mittlerer Abschluss [23]; Fachoberschulreife [29; 32], Mittlerer Bildungsabschluss [28; 31-32], Mittlere Reife [30]; Qualifizierter Sekundarabschluss I [16].

В земле Северный Рейн-Вестфалия [32] и Бранденбурге [29] используются два варианта данной номинации (Mittlerer Schulabschluss / Fachoberschulreife; Realschulabschluss/Fachoberschulreife), которые в текстах нормативно-правовых актов указаны как синонимы.

В свободном государстве Бавария [15] наряду с Realschulabschluss, функционирует равная ему по значению единица Wirtschaftsschulabschluss. Отличия заключаются в типе учебного заведения, по окончанию которого можно получить свидетельство.

Все вышеперечисленные лексические единицы данного синонимического ряда - территориальные дублеты.

4) «Расширенный аттестат, свидетельствующий об окончании десятого класса основной школы».

Имеет два синонимичных варианта:

Erweiterte Berufsbildungsreife (используется на территории земель Берлин [19] и Бремен [20], Бранденбург [29]); Erweiterter Hauptschulabschluss (земли Бранденбург [29]). 
4) «Расширенный атmестат, свидетельствующий об окончании десятого класса реальной школы».

Представлен тремя синонимами:

Erweiterter Realschulabschluss употребляется на территории земли Саксония-Анхальт [27], Erweiterter Sekundarabschluss I - на территории земли Нижняя Саксония [33], Qualifizierter Realschulabschluss - на территории земель Гессен [23], Шлезвиг-Гольштейн [28].

Следующие единицы относятся к видам документов об окончании второй ступени среднего образования Sekundarstufe II и не имеют синонимов:

1. Zeugnis der Allgemeinen Hochschulreife - свидетельство, дающее право на поступление в высшее учебное заведение. Функционирует на территории всех Германии и выдается после сдачи экзамена Abitur по окончании старших классов гимназии (Gymnasiale oberstufe), школ, с тремя профилями подготовки (Schularten mit drei Bildungsgängen), вечерней гимназии (Abendgymnasium) или колледжа (Kolleg) [25]. В нормативно-правовых актах и текстовых материалах, размещенных на официальных сайтах Министерств, в наименовании данного документы допускается опущение существительного Zeugnis (свидетельство). Однако, номинация Allgemeinen Hochschulreife обозначает не сам документ, а квалификацию, необходимую для поступления в высшее учебное заведение, которую подтверждает выданный документ Zeugnis der Allgemeinen Hochschulreife [22, p. 206].

2. Abschlusszeugnis der Berufsschule - ammecmam об окончании школы профессионального обучения Berufsschule. Номинация используется на территории всей Германии.

3. Abschlusszeugnis der Berufsfachschule - ammeстат об окончании профессиональной школы Berufsfachschule.

4. Zeugnis der Fachgebundenen Hochschulreife - свидетельство, дающее право на обучение в высших учебных заведениях на определенных специальностях. Лексема функционирует в семи регионах. [16; 19-20; 28; 31-32;35].

5. Zeugnis der Fachhochschulreife - свидетельство, выдаваемое по окончании общеобразовательной специализированной школы Fachoberschule, дaem право на поступление в университет прикладных наук Fachhochschule или в профессиональную академию Berufsakademie.

Наименование документов о высшем образовании, выдаваемые в Германии, представлены одной номинацией:

1) Urkunde über die Verleihung des akademischen Grades - свидетельство о присуждении академической степени. Данная номинация служит для обозначения документов, выдаваемых при присуждении степени бакалавра (Bachelor), магистра (Master) или доктора наук (Doktorgrad).

\section{2. Лексические еАинишы, используемые $\Delta$ мя номинашии Аокументов об образовании, вы $а$ аваемых в Российской ФеАерации}

Структура системы образования России установлена Федеральным законом «Об образовании в Российской Федерации» от 29.12.2012 N 273-Ф3 [5], включает следующие уровни:

1. уровень общего образования, в который входит дошкольное образование; начальное общее образование; основное общее образование; среднее общее образование;

2. уровень профессионального образования, включающий среднее профессиональное образование; высшее образование - бакалавриат; высшее образование - специалитет, магистратура; высшее образование - подготовка кадров высшей квалификации. К формам дополнительного образования относится дополнительное образование детей и взрослых и дополнительное профессиональное образование.

Типы документов, выдаваемые по окончании уровней образования, согласно Закону [5] обозначены двумя терминами, образующими семантические группы:

1. документы об образовании и (или) о квалификации;

2. документы об обучении.

\section{I. Аокументы об образовании и (или) о квалификашии}

Лексические единицы данной группы можно разделить на семантические ряды:

1) «Документы о среднем образовании».

1. Ammестат об основном общем образовании, выдается лицам, успешно прошедшим государственную итоговую аттестацию по окончании 9 класса учреждения среднего образования.

2. Ammecmam о среднем общем образовании, выдается лицам, успешно прошедшим государственную итоговую аттестацию по окончании 11 класса учреждения среднего образования.

2) «Документы о среднем профессиональном образовании».

Для номинации документа данного вида в дискурсе русского языка функционирует одна номинация - Диплом о среднем профессиональном образовании, который выдается по окончании профессиональной образовательной организации. 


\section{3) «Документы о высшем образовании».}

Стоит отметить, что Российская Федерация присоединилась к Болонскому процессу в 2003г. [17]. С тех пор в стране проводится соответствующая работа по реформированию высшего образования на федеральном и региональном уровнях, что находит отражение в образовательном дискурсе русского языка.

Семантический ряд «Документы о высшем образовании» представлен следующими номинациями:

1. Диплом бакалавра, подтверждающий получение академической степени бакалавра или квалификации бакалавра [1].

2. Диплом магистра, подтверждающий получение академической степени магистра.

Обе вышеуказанные номинации были введены в образовательный дискурс русского языка с переходом на двухуровневую систему высшего образования в соответствии с международными стандартами Болонских соглашений.

3. Диплом специалиста, подтверждающий окончание программы специалитета. Документ не считается равным диплому магистра и не подтверждает получение академической степени. Однако образовательные программы специалитета и магистратуры, согласно Закону, относятся к одному уровню высшего профессионального образования в РФ.

4) «Документы об окончании программ подготовки научно-педагогических кадров».

1. Диплом об окончании аспирантуры (адъюнктуры);

2. Диплом об окончании ординатуры;

3. Диплом об окончании ассистентуры-стажировки.

Вышеуказанные номинации можно считать синонимичными. Различия заключаются в направленности образовательных программ, сроках и форме обучения.

5) «Диплом о присуждении ученой степени».

1. Диплом кандидата наук, подтверждающий присвоение ученой степени кандидата наук.

2. Диплом доктора наук, подтверждающий присвоение ученой степени доктора наук.

\section{II. Аокументы об обучении}

К группе относятся следующие лексические единицы:

1. Свидетельство об обучении, выдается лицам с ограниченными возможностями здоровья, обучающихся по адаптированным программам.

2. Свидетельство об освоении дополнительных профессиональных программ.
3. Справка об обучении или периоде обучения, которая выдается лицам, не прошедшим итоговую аттестацию, освоившим часть программы.

\section{3. Сопоставительный анализ выявленных лексических еАинич}

Подводя итоги проведенного исследования, следует отметить, что на всей территории Германии для обозначения документов, свидетельствующих о завершении одной из школьной ступеней образовании, на всей территории Германии используются два термина: Abgangszeugnis (свидетельство об окончании, выдаваемое вместо аттестата учащимся, не достигшим образовательных челей) и Abschlusszeugnis (ammecmam). Нами были выявлены 25 лексических единиц, обозначающих виды Abschlusszeugnis, 20 из которых можно объединить в синонимические ряды, пять номинаций не имеют синонимов, что говорит об их безэкивалентности (Zeugnis der Allgemeinen Hochschulreife, Abschlusszeugnis der Berufsschule, Abschlusszeugnis der Berufsfachschule, Zeugnis der Fachgebundenen Hochschulreife, Zeugnis der Fachhochschulreife).

Лексические единицы, обозначающие виды документов о школьном образовании, образуют следующие синонимические ряды:

1. «Ammecmam о среднем образовании». Является самым многочисленным и состоит из восьми номинаций, использующихся в одиннадцати регионах. Все выявленные единицы - территориальные дублеты.

2. «Aтmестат о неполном среднем образовании». Включает четыре лексические единицы, функционирующих в 12 федеральных землях. Лексемы являются территориальными дублетами.

3. «Квалификационный атmестат об окончании девятого класса основной школы». Представлен тремя лексемами, функционирующими в четырех регионах. Синонимия обусловлена различным орфографическим оформлением и территориальной маркированностью.

4. «Расширенный аттестат, свидетельствующий об окончании десятого класса основной школы». Включает два синонимических варианта номинаций, которые используются в четырех федеральных землях.

5. «Расширенный аттестат, свидетельствующий об окончании десятого класса реальной школы». Представлен тремя синонимами, использующимися в четырех регионах.

Лексические единицы, обозначающие документы о высшем образовании в Германии представлены одной безэквивалентной номинацией, функционирующими на территории всей страны (Urkunde über die Verleihung des akademischen Grades). 
Среди всех выявленных лексических единиц восемь представляют собой сложные композиты, состоящие из нескольких элементов, 20 номинаций - словосочетания.

Семантически значимыми компонентами лексем выступают: "Abschluss" / "Abschlusszeugnis" (ammecmam), "Reife" (зрелость), "Zeugnis" (свидетельство), "Urkunde" (свидетельство, удостоверение).

Отдельно стоит отметить номинации-словосочетания, содержащие в своем составе существительные с компонентом "Reife" (зрелость). Подобные существительные представляют собой сложные композиты, состоящий из двух семантически значимых компонентов: наименование учреждения + "Reife" (зрелость). В качестве наименования учреждения указывается не та организация, по окончании которой выдан данный документ, а учреждение, в котором можно продолжить обучение. Например, Zeugnis der Fachhochschulreife - свидетельство, выдаваемое по окончании общеобразовательной специализированной школы Fachoberschule. Существительное Fachhochschulreife состоит из двух семантически значимых частей: Fachhochschule - университет прикладных наук, поступление в который дает право данное свидетельство, + "Reife" (зрелость).

В образовательном дискурсе русского языка номинации, обозначающие документы об образовании, обозначены двумя терминами, каждый из которых составляет семантическую группу: документы об образовании и (или) о квалификации, документы об обучении.

Нами были выявлены 11 лексических единиц, входящих в группу документов об образовании и (или) о квалификации, семь из которых образуют семантические ряды («Документы о среднем образовании», в который входят две номинации, "Документы о высшем образовании», представленный тремя лексическими единицами, «Диплом о присуждении ученой степени», в который входят две лексемы). Три номинации данной группы являются синонимичными (Диплом об окончании аспирантуры (адъюнктуры); Диплом об окончании ординатуры; Диплом об окончании ассистентуры-стажировки). Одна лексема - безэквивалентной (Диплом о среднем профессиональном образовании).

В группу Документы об обучении входят три безэквивалентные номинации (Свидетельство об обучении, Свидетельство об освоении дополнительных профессиональных программ, Справка об обучении или периоде обучения).

Лексические единицы, используемые для наименования документов об образовании в образовательном дискурсе русского языка, представлены словосочетаниями, семантически значимыми компонентами которых высту- пают: «Аттестат», «Диплом», «Свидетельство», «Справка». Сложные композиты, состоящие из нескольких элементов, в номинациях документов не используются.

\section{Зак^ючение}

В результате проведенного исследования нами выявлены следующие лингвостилистические особенности лексических единиц, обозначающих документы об образовании:

1. в образовательном дискурсе немецкого и русского языков наименования документов об образовании представляют собой словосочетания. Однако в немецком языке номинации могут быть не только словосочетаниями, но и сложными композитами, что является традиционным для данного языка способом словообразования;

2. в обоих исследуемых языках есть понятие документа, выдаваемого лицам, прошедшим определенный период обучения, но не освоившим образовательную программу в нужном объеме: Abgangszeugnis / Справка об обучении или периоде обучения;

3. семантическими значимыми компонентами лексических единиц, функционирующие в образовательном дискурсе как немецкого, так и русского языков, являются: "Abschluss / Abschlusszeugnis" / «Ammecmam», "Zeugnis" / «Свидетельство». Однако номинации, в которые входят вышеуказанные элементы, не могут считаться полностью эквивалентными по своему значению. Например, в отличие от России, в Германии может быть выдан не только документ об окончании учебного заведения, но и свидетельство, дающее право на поступление в определенную образовательную организацию (Zeugnis der Fachhochschulreife).

4. выявлены семантически значимые компоненты, функционирующие в образовательном дискурсе только немецкого ("Reife" (зрелость), "Urkunde" (свидетельство, удостоверение)) или только русского («Диплом», «Справка») языка;

5. для обоих языков характерно явление синонимии, однако шире оно представлено в образовательном дискурсе немецкого языка. Установленная нами синонимия лексических единиц, использующихся для номинации документов об образовании школьной системы образования Германии, обусловлена тем фактом, что она является децентрализованной, ключевую роль в регулировании образования играют нормативно-правовые акты в каждом отдельном регионе, поэтому синонимами номинаций могут выступать и их территориальные дублеты. В Российской Федерации система образования централизованная. Синонимы образуются из номинаций не по принципу их регионального использования, а в зависимости 
от направленности образовательной программы.

В заключение отметим, что данная работа намечает перспективы дальнейшего исследования лингвостилистических особенностей лексических единиц образовательного дискурса немецкого и русского языков, необходимость которого обусловлена актуальностью избранной темы. Дальнейшее изучение проблемы предполагает исследование единиц различных дискурсивных областей (участники образовательного процесса, органы управления образованием и др.), необходимых для расширения уже имеющихся знаний о системе образования России и Германии и определения специфики немецкоязычного и русскоязычного дискурсов образования.

\section{ЛИТЕРАТУРА}

1. Академик [Электронный ресурс]. URL: http://dic.academic.ru/ (дата обращения: 01.03.2021).

2. Артюхова И.С. Аксиологические основания концептуального анализа образовательного дискурса // Universum: психология и 0бразование. 2016. № 9 (27). C. 7-10.

3. Богуцкая И.Н. Школьный образовательный дискурс (лингвокультурологические основы его формирования): дисс. ... к. филол. н. Тюмень, 2010. 222 с.

4. Добренькова Е.В. Социальная морфология образовательного дискурса: теоретико-методологический анализ: автореф. дисс. … д. соц. н. М., 2007. 49 с.

5. 06 образовании в Российской Федерации [Электронный ресурс]: Федеральный Закон от 29.12.2012 № 273-Ф3 (последняя редакция). URL: http://www. consultant.ru/document/cons_doc_LAW_140174/ (дата обращения: 01.03.2021).

6. Официальный интернет-ресурс Минпросвещения России [Электронный ресурc]. URL: https://edu.gov.ru (дата обращения: 01.03.2021).

7. Официальный интернет-ресурс Министерства образования и науки Российской Федерации [Электронный ресурc]. URL: https://minobrnauki.gov.ru (дата обращения: 01.03.2021).

8. Пеньков Б.В. Дифференциация институционального дискурса: образовательный дискурс // Вестник Российского университета дружбы народов. Серия: Лингвистика. 2009. № 4. С. 63-68.

9. Полонский В.М. Словарь по образованию и педагогике. М.: Высш. шк., 2004. 512 с.

10. Российское образование [Электронный ресурс]: федеральный портал. URL: http://www.edu.ru/ (дата обращения: 01.03.2021).

11. Селезнева Н.А. Словарь согласованных терминов и определений в области образования государств - участников Содружества Независимых Государств. М.: НИТУ «МИСиС», 2012. 244 c.

12. Сластенин В.А., Исаев И.Ф., Шиянов Е.Н. Педагогика: учебное пособие для студентов высш. пед. учеб. заведений / под ред. В.А. Сластенина. М.: Академия, 2002.576 с.

13. Трушина М.К. Лингвокультурный аспект использования эвфемистического высказывания в педагогическом дискурсе (на материале книг Up the Down Staircase Бел Кауфман, The Wednesday Wars Гэри Шмидта и их переводов на русский язык): дисс. ... к. филол. н. Мытищи, 2020. 183 с.

14. Юзманов П.Р. Категория информативности в русском и немецком документном образовательном тексте/дискурсе: дисс. ... к. филол. н. Тюмень, 2012. 236 c.

15. Bayerisches Staatsministerium für Unterricht und Kultus [Электронный ресурc]. URL: https://www.km.bayern.de (дата обращения: 01.03.2021).

16. Bildungsserver Rheinland-Pfalz [Электронный ресурс]. URL: https://bildung-rp.de (дата обращения: 01.03.2021).

17. Glossary on the Bologna Process English — German — Russian // Beiträge zur Hochschulpolitik 7/2006. URL: https://www.hrk.de/fileadmin/redaktion/hrk/02Dokumente/02-10-Publikationsdatenbank/Beitr-2006-07_Glossary_Bologna.pdf (дата обращения: 01.03.2021).

18. Das Grundgesetz für die Bundesrepublik Deutschland [Электронный ресурс]. URL: http://www.gesetze-im-internet.de/gg/art_7.html (дата обращения: 01.03.2021).

19. Das offizielle Hauptstadt portal Berlin.de [Электронный ресурc]. URL: https://www.berlin.de (дата обращения: 01.03.2021).

20. Die Senatorin für Kinder und Bildung der Freien Hansestadt Bremen [Электронный ресурс]. URL: https://www.bildung.bremen.de (дата обращения: 01.03.2021).

21. Duden online-Wörterbuch [Электронный ресурc]. URL: https://www.duden.de (дата обращения: 01.03.2021).

22. European Glossary on Education: Educational Institutions. Volume 1 (5). Second edition. Brussels: Eurydice, 2004. 264 p.

23. Hessisches Kultusministerium [Электронный ресурс]. URL: https://kultusministerium.hessen.de (дата обращения: 01.03.2021).

24. Hochschulrahmengesetz [Электронный ресурc]. URL: https://www.gesetze-im-internet.de/hrg/index.html\#ВJNR001850976BJNE003604320 (дата обращения: 01.03.2021).

25. Kultminister Konferenz [Электронный ресурc]. URL: https://www.kmk.org (дата обращения: 01.03.2021).

26. Landesportal Saarland [Электронный ресурc]. URL: https://www.saarland.de (дата обращения: 01.03.2021).

27. Landesportal Sachsen-Anhalt [Электронный ресурc]. URL: https://bildung.sachsen-anhalt.de (дата обращения: 01.03.2021).

28. Landesportal Schleswig-Holstein [Электронный ресурc]. URL: https://www.schleswig-holstein.de (дата обращения: 01.03.2021).

29. Ministerium für Bildung, Jugend und Sport (MBJS) [Электронный ресурс]. URL: https://mbjs.brandenburg.de (дата обращения: 01.03.2021).

30. Ministerium für Bildung, Wissenschaft und Kultur Mecklenburg-Vorpommern [Электронный ресурс]. URL: https://www.regierung-mv.de (дата обращения: 01.03.2021).

31. Ministerium für Kultus, Jugend und Sport Baden-Württemberg [Электронный ресурс]. URL: https://km-bw.de/ (дата обращения: 01.03.2021).

32. Ministerium für Schule und Bildung des Landes Nordrhein-Westfalen [Электронный ресурс]. URL: https://www.schulministerium.nrw.de (дата обращения: 01.03.2021). 
33. Niedersächsischen Kultusministerium [Электронный ресурc]. URL: https://www.mk.niedersachsen.de (дата обращения: 01.03.2021).

34. Staatsministerium für Kultus [Электронный ресурc]. URL: https://www.schule.sachsen.de (дата обращения: 01.03.2021).

35. Stadtportal Hamburger [Электронный ресурc]. URL: https://www.hamburg.de (дата обращения: 01.03.2021).

36. Thüringer Ministerium für Bildung, Jugend und Sport [Электронный ресурc]. URL: https://bildung.thueringen.de (дата обращения: 01.03.2021).

(c) Руденко Татьяна Ивановна (ti.rudenko@mpgu.edu).

Журнал «Современная наука: актуальные проблемы теории и практики»

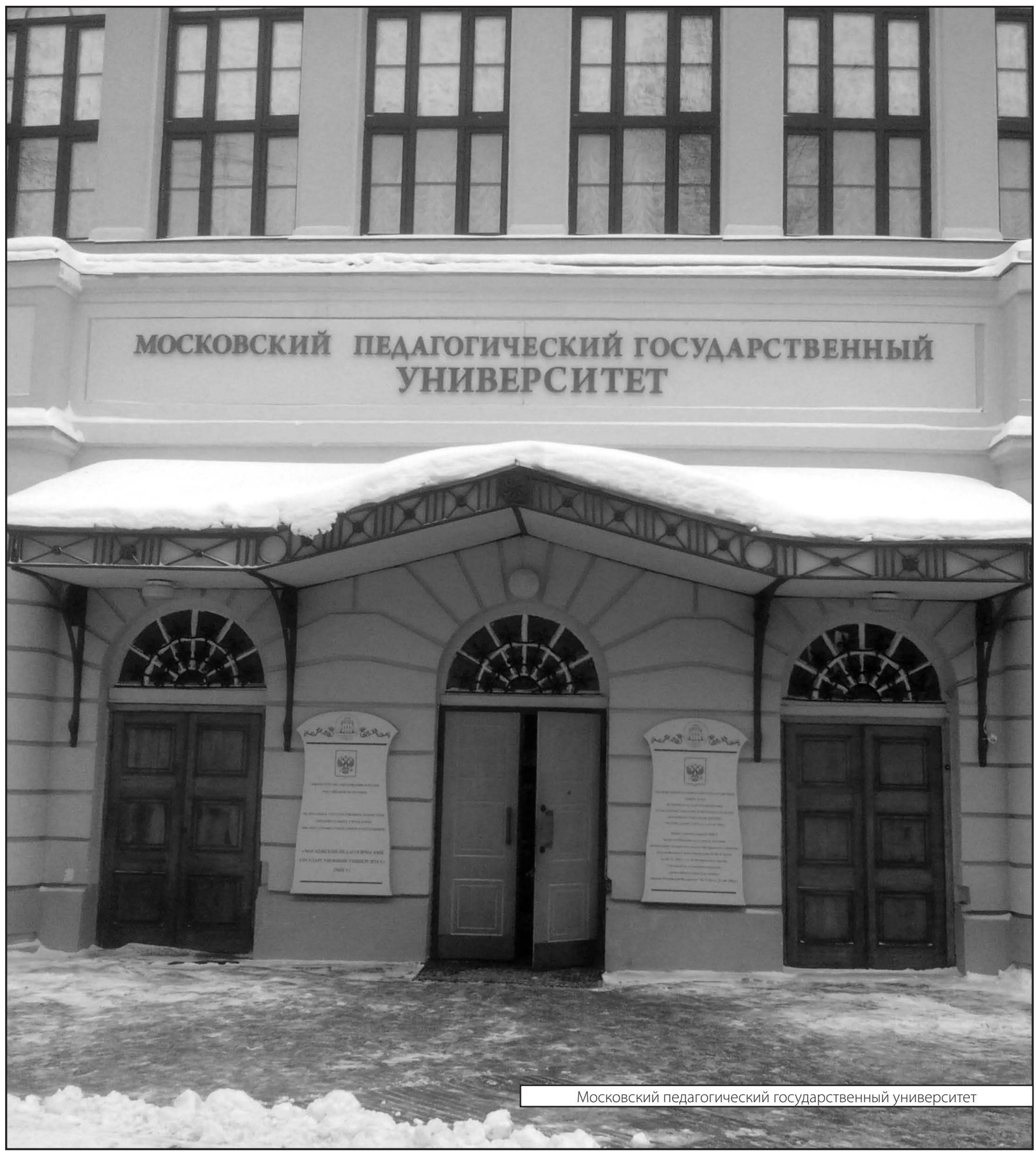

